\title{
Prognostic factors of extracorporeal shock wave therapy for tendinopathies
}

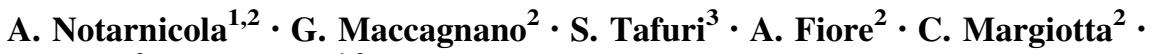 \\ V. Pesce $^{2} \cdot$ B. Moretti ${ }^{1,2}$
}

Received: 25 January 2015/Accepted: 6 May 2015/Published online: 16 May 2015

(C) Istituto Ortopedico Rizzoli 2015

\begin{abstract}
Introduction Extracorporeal shock wave therapy is very widely used for the management of tendinopathies and plantar fasciitis.

Aim The aim of the study is to determine whether there are prognostic factors that may influence the outcome of extracorporeal shock wave therapy for these diseases.

Methods Three hundred fifty-five patients were analyzed 2 months after shock wave treatment for rotator cuff tendinitis, epicondylitis, Achilles tendinopathy, trocanteritis, jumper's knee or plantar fasciitis. We recorded the epidemiological, clinical and treatment protocol, and these data were correlated with treatment outcome.

Results Clinical improvement was achieved in $45.9 \%$ of these patients. We discovered that laterality different to the dominant limb $(p<0.0001)$ and repeated shock wave treatments $(p=0.004)$ are prognostic factors in an unsuccessful therapy, while being male $(p=0.015)$ and a high body mass index $(p=0.004)$ are factors for success. We found no differences in relation to age, diet, blood type,
\end{abstract}

A. Notarnicola

angelanotarnicola@yahoo.it

1 Course of Motor and Sports Sciences, Department of Medical Sciences of Basis, Neurosciences and Organs of Sense, Faculty of Medicine and Surgery, University of Study of Bari, Lungomare Starita 1, 70123 Bari, Italy

2 Orthopedics Section, Department of Medical Sciences of Basis, Neurosciences and Organs of Sense, Faculty of Medicine and Surgery, University of Study of Bari, General Hospital, Piazza Giulio Cesare 11, 70124 Bari, Italy

3 Department of Biomedical Sciences and Human Oncology, Faculty of Medicine and Surgery, University of Study of Bari, General Hospital, Piazza Giulio Cesare 11, 70124 Bari, Italy work or sport activity, presence of co-morbidities, drugs, type of tendinopathy, density of energy delivered and other physiotherapy treatment. Knowledge of these prognostic factors may lead to improved insight for physicians and physiotherapists to predict the extent of the recovery and adjust rehabilitation and patient expectations accordingly.

Keywords Risk factor - Prognosis - Tendinopathy · Shock waves

\section{Introduction}

Overload of tendons and fascia is a common overuse injury in the athletic and working populations; it is the main reason for consultation for a musculoskeletal complaint and corresponds to around $30 \%$ of all such consultations with a general practitioner $[1,2]$. Changes in the connective matrix composition are in part mediated by inflammatory mediators and metalloproteinase enzymes and are consistent with changes in cell-mediated matrix remodeling that precede the onset of clinical symptoms $[3,4]$. The etiology of tendinopathy and plantar fasciitis seems to be a multifactorial process, involving promoting factors that are intrinsic or extrinsic, working either alone or in combination [5]. These diseases have similar pathogenesis, and they are degenerative conditions caused by repetitive partial tearing of the tendon or fascia with associated chronic inflammation. They are usually a self-limiting condition and treated non-operatively in the majority of patients [6]. However, 10-20\% develop chronic pain and may require surgery $[7,8]$.

Extracorporeal shock wave therapy (ESWT) has been proposed as a potential method of treating patients with chronic disease [9-14]. Shock waves (SWs) are defined as 
transient pressure oscillations that propagate in three dimensions and typically bring about a clear increase in pressure within a few nanoseconds [15]. There are very rapidly rising positive pressure impulses from 5 to $120 \mathrm{MPa}$ in around $5 \mathrm{~ns}$, followed by a decrease to negative pressure values of $-20 \mathrm{MPa}$ [16]. When a SW bombards a tissue, it should be consider the presence of two effects: the stress-related phenomenon induced by the ultra-short rise time around $5 \mathrm{~ns}$ and the cavitation bubbles produced at the interface between the solid and the surrounding liquid. These two physical effects work synergically to produce the SW action. ESWT stimulates soft tissue healing primarily by inhibiting afferent pain-receptor function within the first hours [17], followed, in the next few days, by downregulating the expression of inflammatory cytokines [18], and by enhancing the angiogenesis [19] and, at around the 28th-30th day, by improving cellular proliferation and the synthesis of the extra-cellular matrix [20].

Numerous studies have evaluated the efficacy of ESWT as a method of managing musculoskeletal diseases such as lateral humeral epicondylitis, Achilles tendinitis, rotator cuff tendinopathy, jumper's knee, trocanteritis and plantar fasciitis [9-14]. Furthermore, several experimental studies have reported that ESWT accelerates tendon and fascia healing by triggering neovascularization and improving the local blood supply and tissue regeneration [21-24]. In the management of these diseases, the efficiency of ESWT was assessed by previous randomized controlled clinical trials, yielding a success rate ranging from 43 to $75 \%[25,26]$. An interesting question is which patient is amenable to ESWT. Epidemiological and clinical characteristics, as well as energy parameters in treatment protocol, could influence the outcome of ESWT therapy.

As far as we know, no clinical study has been conducted investigating prognostic factors for SW therapeutic outcomes. Better knowledge of these prognostic factors may lead to improved insight for orthopedic surgeons, physiatrists and physiotherapists to predict the extent of the recovery and adjust rehabilitation and patient expectations accordingly.

\section{Materials and methods}

An observational study was performed to verify the influence of prognostic factors on the success of the therapy for multidistrectual tendinopathies and plantar fasciitis. Patients with one of these diseases were considered candidates for ESWT if they had persistent severe pain and disability not responding to at least 6 months of adequate non-operative treatment and if they did not have massive tendon tears to treat surgically [27].
Between July 2013 and July 2014, personal, clinical and other data relating to the treatment and therapeutical outcome on all the patients who had a follow-up visit at our clinic 2 months after ESWT were collected. Institutional review board approval was obtained for this study protocol. The patients were informed and gave their written consent to be involved in the study. Annually, around 700 consecutive patients underwent ESWT for musculoskeletal diseases at the authors' institution, which is a regional and national referral center for this kind of therapy. Inclusion criteria were: age over 18 years old; a SW treatment for one of the following conditions that are rotator cuff tendinitis, epicondylitis, Achilles tendinopathy, trocanteritis, jumper's knee or plantar fasciitis; persistent severe pain and disability corresponding to a score of 3 or 4 of Roles and Maudsley score [28]. Exclusion criteria were: medical problems that would have been contraindicated for ESWT; corticosteroid injection before the study; medical therapy in the previous 3 months; previous surgery on the treated area; advanced osteoarthritis; massive tendon injury and axis deviation.

At the pre-treatment, 440 patients were eligible for the study, but a total of 355 patients were revaluated at the 2-month follow-up. The main reasons for dropping out are interruption of ESWT ( $n=4$ patients), lack of time for the follow-up visit ( $n=36$ patients), switching to other treatments before the follow-up ( $n=37$ patients), such as surgery ( $n=8$ patients). SW treatments were carried out previously by medical staff at our clinic, including two physiatrist in training who were supervised each time by the same physiatrist who is also in charge of the clinic and has 10 years of experience using this kind of treatment. The SW therapy was focused and ultrasound-guided and carried out using an electromagnetic generator (MiniLith SL1, Storz Medical, Italy). In accordance with the literature [9-14] and International Society for Medical Shockwave Treatment guidelines [29], the patients underwent three treatments of ESWT, performed at weekly intervals, with an average of 2000 shocks (1600 impulses for Achilles tendinopathy and epicondylitis, 2400 impulses for calcific tendonitis of the shoulder, 2000 impulses for all the other diseases, respectively), at energy density flux (EDF) between 0.01 and $0.15 \mathrm{~mJ} / \mathrm{mm}^{2}$, according to patients' pain tolerance levels. The pulse repetition frequency was $4 \mathrm{~Hz}$. The valuation included demographic, clinical and therapeutical assessments as described below.

\section{Demographic assessments}

The following epidemiological data were recorded: age, gender, weight, height, body mass index (BMI), diet, blood type, type of work and sporting activity. Occupation was 
self-reported as one of the following choices: professional, manual labor, homemaker, unemployed, retired [30].

\section{Clinical assessments}

The presence of morbidity, arterial hypertension, mellitus diabetes, dyslipidemia, thyroid dysfunction, rheumatic diseases, toxic drugs for the tendon (cortisones, anxiolytics, diuretics, fluoriquinolones) [31] and the simultaneous presence of tendinopathy in another joint were recorded.

\section{Therapeutic assessments}

The condition treated (rotator cuff tendinitis, epicondylitis, Achilles tendinopathy, trocanteritis, jumper's knee, plantar fasciitis), laterality, the average EDF of the SW treatment, any previous SW cycles and any other physiotherapy treatment were noted.

\section{Clinical results}

The Roles and Maudsley score was adopted for the evaluation of the therapeutic outcome [27]. A score of 1, meaning excellent, was given to an absence of pain and a full functional recovery; a score of 2 , meaning good, was given to patients who experienced occasional pain, but had made a satisfactory functional recovery; a score of 3, meaning fair, was awarded when patients experienced discomfort after prolonged activity; a score of 4 , meaning poor, was used when pain limited functionality. Scores 1 and 2 were considered as a clinical improvement and a successful outcome to the treatment, while 3 and 4 with persistent discomfort meant that the therapy was unsuccessful.

\section{Statistical evaluation}

For each patient taking part in the study, we filled in a data collection form. These completed forms were then inserted into a database built using File Maker Pro software (FileMaker, Inc, Santa Clara, CA, USA) and analyzed using STATA MP11 software (StataCorp LP, College Station, TX, USA). Categorical variables were expressed as proportions and continuous variables as averages with an indication of the standard deviation values; for the comparison of the proportions in the "success" group and the "fail" group, we used the Chi-square test, and to compare the averages in the two groups, we used the $t$ student test. To evaluate the possible link between demographic, clinical and relative variables related to the investigation and failure, we carried out a univariate analysis. We then set up a multiple regression model, calculating the odds ratio (OR) values with confidence intervals at $95 \%$ and carried out the Chi-square test. A value of $p<0.05$ was considered to be significant.

\section{Results}

The demographic features of the patients are expressed in Table 1. The population of the study was made up of 195 $(54.9 \%)$ subjects who reported therapeutic success and $160(45.1 \%)$ subjects who reported therapeutic failure. At the pre-treatment, the patients expressed persistent pain and discomfort, corresponding to the Roles and Maudsley scores of $3(62.2 \%)$ and $4(37.8 \%)$. At the follow-up, the distribution of the results of the Roles and Maudsley score was: 53 subjects $(14.9 \%)$ with a score of $1,142(40 \%)$ with a score of 2 subjects, 86 subjects (24.2\%) with a score of 3 and 74 subjects $(20.9 \%)$ with a score of 4 . No correlation was found between the Roles and Maudsley scores at the pre- and the post-treatment $(p>0.05)$. Clinical assessments had no influence on the response to therapy (Table 2). The univariate analysis of the data showed that the non-dominant limb $\quad(O R=4.57 ; \quad 95 \%$ $\mathrm{CI}=2.74-7.61 ; z=67.8 ; p<0.001)$, the bilateral location $\quad(\mathrm{OR}=3.96 ; \quad 95 \% \quad \mathrm{CI}=2.25-6.98 ; \quad z=59.0$; $p<0.0001)$ and the number of ESWT cycles $(\mathrm{OR}=1.49$; $95 \%$ CI $=1.14-1.94 ; z=2.89 ; p=0.004)$ were associated with failure, while being of the male gender $(\mathrm{OR}=0.58 ; \quad 95 \% \quad \mathrm{CI}=0.38-0.90 ; \quad z=-2.43$; $p=0.015$ ) was shown to be a protecting factor (Table 3 ). The multivariate analysis highlighted a greater number of therapy cycles $(\mathrm{OR}=2.1 ; 95 \% \mathrm{CI}=1.3-3.3 ; z=3.04$; $p=0.002)$ as a failure factor, while a higher BMI value $(\mathrm{OR}=0.88 ; \quad 95 \% \quad \mathrm{CI}=0.81-0.96 ; \quad z=-2.85 ; \quad p=$ 0.004 ) was a protecting factor, and the limb (upper or lower) is not a confounding factor $(\mathrm{OR}=0.98 ; 95 \%$ $\mathrm{CI}=0.63-1.50 ; z=0.13 ; p=0.9$ ) (Tables 1, 3). During a treatment for plantar fasciitis, an episode of prechordal pain occurred and electrocardiogram showed a partial block bundle branch. It was not possible to verify or to exclude the correlation between this event and ESWT. No other complications occurred.

\section{Discussion}

Previous clinical studies have investigated the influence of prognostic factors on the results of other conservative and surgical treatments in patients affected by tendinopathies and plantar fasciitis [27, 32-35]. For conservative treatment hand dominance, clinical history of the shoulder condition, severity of the shoulder problem, or shoulder mechanics was not predictive of success [31]. After subacromial corticosteroid injection, patient age, arm 
Table 1 Demographic assessments and distribution in the study population

\begin{tabular}{|c|c|c|c|c|}
\hline Demographic assessments & Total & Success & Failure & Statistical value \\
\hline Total & 355 & $195(54.9 \%)$ & $160(45.1 \%)$ & \\
\hline Male & 137 & $86(62.8 \%)$ & $51(37.2 \%)$ & $\chi^{2}=5.94 ; p=0.015$ \\
\hline Female & 218 & $108(49.5 \%)$ & $110(50.5 \%)$ & \\
\hline Age & $58.2 \pm 11.5$ & $59.2 \pm 11.6$ & $57.0 \pm 11.3$ & $T=1.83 ; p=0.03$ \\
\hline Height & $164.1 \pm 9.0$ & $164.4 \pm 9.6$ & $163.7 \pm 8.2$ & $T=0.74 ; p=0.22$ \\
\hline Weight & $76.3 \pm 14.7$ & $77.8 \pm 14.8$ & $74.6 \pm 14.5$ & $T=2.0 ; p=0.02$ \\
\hline Body mass index (BMI) & $28.2 \pm 4.8$ & $28.7 \pm 4.9$ & $27.5 \pm 4.7$ & $T=1.98 ; p=0.02$ \\
\hline \multicolumn{5}{|l|}{ Diet } \\
\hline Mediterranean diet & $341(96 \%)$ & $183(51.5 \%)$ & $158(44.5 \%)$ & $\chi^{2}=1.3 ; p=0.25$ \\
\hline High protein diet (type Dukan diet) & $14(4 \%)$ & $5(35.7 \%)$ & $9(64.3 \%)$ & $\chi^{2}=2.1 ; p=0.15$ \\
\hline Lactose intolerance & $13(3.7)$ & $7(53.8 \%)$ & $6(46.2 \%)$ & $\chi^{2}=0.003, p=0.95$ \\
\hline \multicolumn{5}{|l|}{ Blood group $^{a}$} \\
\hline A & 93 & $51(54.8 \%)$ & $42(45.2 \%)$ & $\chi^{2}=0.27 ; p=0.60$ \\
\hline $\mathrm{B}$ & 64 & $35(54.7 \%)$ & $29(45.3 \%)$ & $\chi^{2}=0.19 ; p=0.67$ \\
\hline $\mathrm{AB}$ & 19 & $12(63.2 \%)$ & $7(36.8 \%)$ & $\chi^{2}=0.31 ; p=0.58$ \\
\hline $\mathrm{O}$ & 110 & $66(60 \%)$ & $44(40 \%)$ & $\chi^{2}=1.71 ; p=0.191$ \\
\hline $\mathrm{Rh}+$ & 224 & $129(57.6 \%)$ & $95(42.4 \%)$ & $\chi^{2}=0.11 ; p=0.71$ \\
\hline \multicolumn{5}{|l|}{ Occupation $^{\mathrm{b}}$} \\
\hline Professional & 72 & $40(55.6 \%)$ & $32(44.4 \%)$ & $\chi^{2}=3.1 ; p=0.54$ \\
\hline Manual labor & 73 & $38(52.1 \%)$ & $35(47.9 \%)$ & \\
\hline Homemaker & 123 & $60(48.8 \%)$ & $63(51.2 \%)$ & \\
\hline Unemployed & 4 & $3(75.0 \%)$ & $1(25.0 \%)$ & \\
\hline Retired & 67 & $40(59.7 \%)$ & $27(40.3 \%)$ & \\
\hline Sport activity & 74 & $36(48.6 \%)$ & $38(51.3 \%)$ & $\chi^{2}=0.90 ; p=0.34$ \\
\hline
\end{tabular}

Values are expressed as mean ( \pm standard deviation) and percentage. In the population of the study, $54.9 \%$ of the patients reported therapeutic success and $45.1 \%$ of the patients reported therapeutic failure. The BMI and male gender were prognostic factors for success

${ }^{a}$ Blood group was not known for 69 subjects

b 16 subjects did not report the work

Table 2 Clinical assessments and distribution in the study population

\begin{tabular}{|c|c|c|c|c|}
\hline Clinical assessments & Total & Success & Failure & Statistical value \\
\hline Hypertension & $156(43.9 \%)$ & $92(59 \%)$ & $64(41 \%)$ & $\chi^{2}=2.10 ; p=0.15$ \\
\hline Diabetes mellitus & $58(16.3 \%)$ & $32(55.2 \%)$ & $26(44.8 \%)$ & $\begin{array}{l}\chi^{2}=0.004 \\
\quad p=0.95\end{array}$ \\
\hline Dyslipidemia & $120(33.8 \%)$ & $63(52.5 \%)$ & $57(47.5 \%)$ & $\chi^{2}=0.30 ; p=0.58$ \\
\hline Hypothyroidism & $58(16.3 \%)$ & $28(48.3 \%)$ & $30(51.7 \%)$ & $\chi^{2}=1.13 ; p=0.29$ \\
\hline Rheumatic diseases & $73(20.6 \%)$ & $38(52.1 \%)$ & $35(47.9 \%)$ & $\chi^{2}=0.25 ; p=0.61$ \\
\hline $\begin{array}{l}\text { Toxic drugs for the tendon (cortisone, anxiolytics, diuretics, } \\
\text { fluoroquinolones) }\end{array}$ & $92(25.9 \%)$ & $48(52.2 \%)$ & $44(47.8 \%)$ & $\chi^{2}=0.31 ; p=0.58$ \\
\hline Tendinopathy in other side & $26(7.3 \%)$ & $14(53.8 \%)$ & $12(46.2 \%)$ & $\begin{array}{c}\chi^{2}=0.007 \\
p=0.93\end{array}$ \\
\hline
\end{tabular}

Values are expressed as mean and percentage. None of these conditions had influence on the response to therapy

dominance, duration and severity of symptoms, sex, status of tendon and baseline activity were not predictive of failure [33]. In arthroscopic treatment for tendinopathies of the shoulder, the researchers found that age and work were responsible for failure, while being of the male gender is associated with a higher therapeutic success rate [28, 34, 
Table 3 Therapeutic assessments and distribution in the study population

\begin{tabular}{|c|c|c|c|c|}
\hline Therapeutic assessments & Total & Success & Failure & Statistical value \\
\hline \multicolumn{5}{|l|}{ Type of tendinopathy } \\
\hline Rotator cuff tendinitis & $131(36.9 \%)$ & $68(51.9 \%)$ & $63(48.1 \%)$ & \multirow[t]{6}{*}{$\chi^{2}=2.46 ; p=0.87$} \\
\hline Epicondylitis & $35(9.6 \%)$ & $11(31.4 \%)$ & $24(68.6 \%)$ & \\
\hline Trocanteritis & $6(1.7 \%)$ & $3(50 \%)$ & $3(50 \%)$ & \\
\hline Achilles tendinopathy & $38(10.7 \%)$ & $20(52.6 \%)$ & $18(47.4 \%)$ & \\
\hline Plantar fascitis & $135(38 \%)$ & $58(42.9 \%)$ & $77(57.1 \%)$ & \\
\hline Jumper's knee & $10(2.8 \%)$ & $6(60 \%)$ & $4(40 \%)$ & \\
\hline Total & 355 & & & \\
\hline \multicolumn{5}{|l|}{ Side } \\
\hline Bilateral side & 72 & $32(44.4 \%)$ & $40(55.6 \%)$ & $\chi^{2}=3.25 ; p=0.07$ \\
\hline Dominant limb & 233 & $125(53.6 \%)$ & $108(46.4 \%)$ & $\chi^{2}=0.09 ; p=0.77$ \\
\hline Non-dominant limb & 194 & $94(48.5 \%)$ & $100(51.5 \%)$ & $\chi^{2}=4.0 ; p=0.046$ \\
\hline \multicolumn{5}{|l|}{ ESWT } \\
\hline Energy Density Flux (EDF) $\left(\mathrm{mJ} / \mathrm{mm}^{2}\right)$ & $0.089 \pm 0.06$ & $0.087 \pm 0.056$ & $0.091 \pm 0.064$ & $T=-0.69 ; p=0.24$ \\
\hline Series of SW treatment & $1.56 \pm 0.84$ & $1.70 \pm 1.01$ & $1.43 \pm 0.65$ & $T=-3.02 ; p=0.0013$ \\
\hline Other physical therapy & $340(95.8 \%)$ & $182(53.5 \%)$ & $158(46.5 \%)$ & $\chi^{2}=0.28 ; p=0.59$ \\
\hline
\end{tabular}

Values are expressed as mean ( \pm standard deviation) and percentage. The univariate analysis of the data showed that the non-dominant limb, the bilateral location and the number of ESWT cycles were associated with ESWT failure

35]. Clinical-epidemiological characteristics, such as ethnicity, smoking, dominance, number of tendons affected, and socioeconomical level, are not associated with failure.

In this year-long case study on treatment using ESWT, a success rate of $54.9 \%$ in patients treated for multidistrectual tendinopathies and plantar fasciitis was found. These results are consistent with those published in previous works [9-14, 25, 26]. This is the first study to analyze prognostic factors predictive of ESWT results in patients with musculoskeletal diseases. It was revealed that only side of the limb and number of sessions were prognostic factors negatively influencing clinical improvement after ESWT. A different laterality to the dominant limb (nondominant or bilateral limb) was another prognostic factor for therapy failure. A better possibility of limiting the functional damage in subjects with disease in the dominant limb compared to subjects with disease in the non-dominant limb was found. We linked this to better training of the dominant limb. The tendency to use one side of the body in preference to the other originates from both genetic sources and development after birth [36]. Having a preferred side can cause asymmetries, both as a primary cause and as a secondary cause through strength and neural development resulting from favored use and consequent training of the dominant side $[37,38]$. Also the bilateral site of the pathology was a prognostic failure factor. In this case, continued overload, and not being able to substitute it with the other limb, could be the reason behind for failure.

A greater number of therapeutic cycles have also been linked to a higher rate of therapy failure. There is evidence for an inherited predisposition contributing to the risk of tendon and fascia diseases [39]. For this reason, we hypothesize that there are patients who are therefore genetically non-responders to this therapy. The genetic hypothesis could explain why repeated therapy cycles continue to be ineffective. It could be useful to evaluate the influence of polymorphisms in the endothelial nitric oxide synthase (eNOS) gene on prognosis of patients [40, 41]. On the other hand, we need to consider the possible negative effects of repeated therapy cycles. Until now past studies have looked at the proliferative effect of SW on tenocytes $[21,42]$, while there have not been any in vivo studies on prolonged SW cycles on tendon tissue. In the urological field, the risk of developing chronic fibrotic lesions after lithotripsy in relation to the number of SW treatment sessions has been documented [43]. In treating connective tissues, the formation of a hematoma and the following inflammation phase, recall stromal stem cells, which differentiate into fibroblasts, would lead to the formation of fibrotic tissue [44, 45]. Repeated cycles of SW could be responsible for a metaplasia of fibrous tissue in the tendon and in fascia, which could explain functional impairment and treatment failure.

In this study, it was revealed that only gender and high BMI were prognostic factors positively influencing clinical improvement after ESWT. Being of the male gender as a prognostic factor in the success of the therapy may be a fact that contrasts with the notion that being of the male gender is actually a risk factor in the onset of tendinopathy and fasciitis plantar [30]. Confirming these results, it is 
necessary to point out that the male gender was shown to be a protective factor even after tendon surgery $[35,46]$. Several explanations were provided: men may experience less emotional difficulties and have a different symptom perception than women; men may consider certain activities that are more difficult after a treatment (e.g., dressing and grooming) to be less important than women do; male patients tend not to delay consulting specialists and postpone treatment, avoiding the worsening of the problem [35, 47]. On the other hand, hormonal influence could justify the different gender reactions [48]. High levels of estrogen in relation to the variability of the hormonal cycle cause an increase in the stiffness of the tendon. These findings link estrogen to a chronic, rather than an acute, impact on connective tissue behavior. Men, not being subject to the action of high levels of estrogen, could be protected in the therapeutic outcome.

High BMI values have been linked to better reactions to treatment using ESWT. High body weight/adiposity is a risk factor in the onset of tendinopathy [30]. Different theories can be put forward to explain this contradictory result. One theory is biological: Adipose tissue is rich in stem cells and growth factors enhancing the biostimulating effects of the SW therapy [48]. Another theory is physical. The diffusion of shockwave follows the physical laws of the acoustic waves being transmitted in reflection and absorbtion, which are related to the characteristics of the medium and are inevitably affected by the diversity in density and by the impedance of the skin, fat, muscle and bone. Adipose tissue, presenting an acoustic impedance close to that of water, allows acoustic waves to pass and reach underlying tissue $[49,50]$.

There were no differences in response between the various tendons treated even though there were better outcomes for jumper's knee, Achilles tendinopathy and rotator cuff tendinitis and worse outcomes for epicondylitis. The simultaneous presence of other tendinopathies had no influence on the final outcome. The response to SW treatment was not influenced by energy parameters of the treatment protocol which was modified according to the patient's tolerability. There were no differences shown between low and medium-high energy in previous works either [51, 52]. The link to other physiotherapy treatments did not show better results. Patients showed good adherence to other treatments. Previous studies advise the association of eccentric exercises to optimize results [53].

The response to SW therapy is not influenced by tendinopathy risk factors. Tendinopathies and plantar fasciitis are more frequent in subjects of $>40$ years of age. The aging tendon is characterized by a low rate of metabolism, a progressive decrease in elasticity and tensile strength and a decreasing tendon blood flow; thus, age would be regarded as an important predisposing factor in the occurrence of tendinopathy [54-56] and to poor prognosis with non-operative management [57] and surgery [58-61]. Systematic diseases (hypertension, mellitus diabetes, dyslipidemia, insulin resistance, rheumatologic disease) [62-68] or the assumption of drugs (cortisone, anxiolytics, diuretics, fluoroquinolones) $[30,65,67]$ damage microcirculation in tendon tissue. Hormonal imbalances (particularly, hypothyroidism) compromise the metabolic capabilities of tenocytes [69, 70]. Diet high in protein foods can contribute to or aggravate inflammation of the tendons in your body $[30,71]$. The ABO gene encodes for transferases could also determine some types of glycoproteins found within the ground tendons substance [72]. Subjects with $\mathrm{O}$ and $\mathrm{Rh}+$ blood types are more at risk from tendinopathies. Work overload or sport can put stress on tendon fibers [73]. It should be hypothesized that the biostimulating action of the SW on tendon fibers and on the extra-cellular matrix may have helped to limit the negative influence of these risk factors which were not found to be prognostic factors in the therapeutic outcome.

The investigation's weak point is its observational design, which resulted in the loss of subjects who, after undergoing ESWT, did not come back to the follow-up scheduled after treatment was finished. No ecographic evaluation was conducted assessing the tendon or fascia morphology at follow-up and evaluating the potential differences with pre-treatment parameters. Another restriction is the absence of a control group, which received other physiotherapy or a placebo treatment. As far as diet is concerned, we recorded the diet reported by the patient. It would be interesting, in further clinical studies, to provide patients with a diary to record types and portions of protein, sugars and fats for each meal, considering the fact that an excess of complex sugars, fat and acidic foods can damage tendon tissue [71]. It would be interesting to see whether these conditions could also affect the therapeutic outcome. In this study, we verified the therapeutic performance in several districts. In future studies, for each specific musculoskeletal disease, it would be useful to gather data relative to specific functional scales and instrumental examinations, which in this study could not be compared. Despite these limitations, this study demonstrates that the success of ESWT correlates with some demographic and therapeutic assessments. Another strong point of the study is the numerous cases.

\section{Conclusions}

In conclusion, after SW treatment for tendinopathies and plantar fasciitis, the success rate was $54.9 \%$. A high BMI and male gender are prognostic factors for improvement. On the other hand, non-dominant or bilateral limb and 
repeated therapy cycles are prognostic factors responsible for failure. One can assume that the treatment protocol should be modified on the basis of these data. In case of a non-dominant or bilateral limb, it could be useful increasing the number of rehabilitative sessions for joint recuperation and occupational therapy. Non-responder patients in the second or more SW cycles should promptly be directed toward a different kind of treatment. Treatment of subjects with reduced fat mass should need to increase the total energy dosage administered. The future of ESWT research should be to define a specific algorithm, which is able to direct the patient to the most appropriate protocol of therapy.

Acknowledgments The authors thank Mrs Catriona Macleod B.A. for language revision.

Conflict of interest None.

\section{References}

1. Forde MS, Punnett L, Wegman DH (2005) Prevalence of musculoskeletal disorders in union ironworkers. J Occup Environ Hyg 2:203-212

2. Riley G (2008) Tendinopathy-from basic science to treatment. Nat Clin Pract Rheumatol 4:82-89

3. Jarvinen TA, Kannus P, Maffulli N, Khan KM (2005) Achilles tendon disorders: etiology and epidemiology. Foot Ankle Clin 10:255-266

4. Scott A, Ashe MC (2006) Common tendinopathies in the upper and lower extremities. Curr Sports Med Rep 5:233-241

5. Fredberg U, Stengaard-Pedersen K (2008) Chronic tendinopathy tissue pathology, pain mechanisms, and etiology with a special focus on inflammation. Scand J Med Sci Sports 18:3-15

6. Roche AJ, Calder JD (2013) Achilles tendinopathy: a review of the current concepts of treatment. Bone Joint J 95-B(10): 1299-1307

7. Ahmad Z, Siddiqui N, Malik SS, Abdus-Samee M, TytherleighStrong G, Rushton N (2013) Lateral epicondylitis: a review of pathology and management. Bone Joint J 95-B(9):1158-1164

8. Childress MA, Beutler A (2013) Management of chronic tendon injuries. Am Fam Physician 87(7):486-490

9. Bannuru RR, Flavin NE, Vaysbrot E, Harvey W, McAlindon T (2014) High-energy extracorporeal shock-wave therapy for treating chronic calcific tendinitis of the shoulder: a systematic review. Ann Intern Med 160(8):542-549

10. van der Worp H, van den Akker-Scheek I, van Schie H, Zwerver J (2013) ESWT for tendinopathy: technology and clinical implications. Knee Surg Sports Traumatol Arthrosc 21(6): 1451-1458

11. Zwerver J, Verhagen E, Hartgens F, van den Akker-Scheek I, Diercks RL (2010) The TOPGAME-study: effectiveness of extracorporeal shockwave therapy in jumping athletes with patellar tendinopathy. Design of a randomised controlled trial. BMC Musculoskelet Disord 11:28

12. Yin MC, Ye J, Yao M, Cui XJ, Xia Y, Shen QX, Tong ZY, Wu XQ, Ma JM, Mo W (2014) Is extracorporeal shock wave therapy clinical efficacy for relief of chronic, recalcitrant plantar fasciitis? A systematic review and meta-analysis of randomized placebo or active-treatment controlled trials. Arch Phys Med Rehabil 95(8):1585-1593
13. Wiegerinck JI, Kerkhoffs GM, van Sterkenburg MN, Sierevelt IN, van Dijk CN (2013) Treatment for insertional Achilles tendinopathy: a systematic review. Knee Surg Sports Traumatol Arthrosc 21(6): 1345-1355

14. Lee SY, Cheng B, Grimmer-Somers K (2011) The midterm effectiveness of extracorporeal shockwave therapy in the management of chronic calcific shoulder tendinitis. J Shoulder Elbow Surg 20(5):845-854

15. Hundt E. Die Physik (1974) BibliographischesInstitut Mannheim. Dudenverlag S360

16. Staudenraus J (1995) In vivo Strasswllenmessung. In: Chaussy (Hrsg) Die Stosswelle in Forschung und Kinik. AttemptoVerlag, pp S21-S26

17. Maier M, Averbeck B, Milz S, Refior HJ, Schmitz C (2003) Substance $\mathrm{P}$ and prostaglandin E2 release after shock wave application to the rabbit femur. Clin Orthop Relat Res 406:237-245

18. Moretti B, Iannone F, Notarnicola A, Lapadula G, Moretti L, Patella V, Garofalo R (2008) Extracorporeal shock waves down-regulate the expression of interleukin-10 and tumor necrosis factor-alpha in osteoarthritic chondrocytes. BMC Musculoskelet Disord 31(9):16

19. Ma HZ, Zeng BF, Li XL (2007) Upregulation of VEGF in subchondral bone of necrotic femoral heads in rabbits with use of extracorporeal shock waves. Calcif Tissue Int 81(2):124-131

20. Bosch G, de Mos M, van Binsbergen R, van Schie HT, van de Lest CH, van Weeren PR (2009) The effect of focused extracorporeal shock wave therapy on collagen matrix and gene expression in normal tendons and ligaments. Equine Vet J 41(4):335-341

21. Chao YH, Tsuang YH, Sun JS, Chen LT, Chiang YF, Wang CC, Chen MH (2008) Effects of shock waves on tenocyte proliferation and extracellular matrix metabolism. Ultrasound Med Biol 34(5):841-852

22. Bosch G, Lin YL, van Schie HT, van De Lest CH, Barneveld A, van Weeren PR (2007) Effect of extracorporeal shock wave therapy on the biochemical composition and metabolic activity of tenocytes in normal tendinous structures in ponies. Equine Vet $\mathbf{J}$ 39(3):226-231

23. Chen YJ, Wang CJ, Yang KD, Kuo YR, Huang HC, Huang YT, Sun YC, Wang FS (2004) Extracorporeal shock waves promote healing of collagenase-induced Achilles tendinitis and increase TGF-beta1 and IGF-I expression. J Orthop Res 22(4):854-861

24. Hsu RW, Hsu WH, Tai CL, Lee KF (2004) Effect of shock-wave therapy on patellar tendinopathy in a rabbit model. J Orthop Res 22(1):221-227

25. Rompe J, Hope C, Küllmer K, Heine J, Bürger R (1996) Analgesic effects of extracorporeal shock wave therapy on chronic tennis elbow. J Bone Joint Surg Br 78:233-237

26. Haake M, König IR, Decker T, Riedel C, Buch M, Müller HH, Extracorporeal Shock Wave Therapy Clinical Trial Group (2002) Extracorporeal shock wave therapy in the treatment of lateral epicondylitis. J Bone Joint Surg Am 84:1982-1991

27. NICE interventional procedures guidance (IPG313) (2009) IPG313 Extracorporeal shockwave therapy for refractory tennis elbow: understanding NICE guidance

28. Roles NC, Maudsley RH (1972) Radial tunnel syndrome: resistant tennis elbow as a nerve entrapment. J Bone Joint Surg $\mathrm{Br}$ 54:499-508

29. Tiele R, New guidelines for ESWT (2009) Newslett ISMST; 5:20. http://www.ismst.com/pdf/ISMST_Newsletter_2009-03_ No5.pdf. Accessed 25 July 2013

30. Brophy RH, Dunn WR, Kuhn JE, MOON Shoulder Group (2014) Shoulder activity level is not associated with the severity of symptomatic, atraumatic rotator cuff tears in patients electing non-operative treatment. Am J Sports Med 42(5):1150-1154

31. Kaux JF, Forthomme B, Goff CL, Crielaard JM, Croisier JL (2011) Current opinions on tendinopathy. J Sports Sci 10(2):238-253 
32. Ginn KA, Cohen ML (2004) Conservative treatment for shoulder pain: prognostic indicators of outcome. Arch Phys Med Rehabil 85:1231-1235

33. Contreras F, Brown HC, Marx RG (2013) Predictors of success of corticosteroid injection for the management of rotator cuff disease. HSS J 9(1):2-5

34. Chung SW, Kim JY, Kim MH, Kim SH, Oh JH (2013) Arthroscopic repair of massive rotator cuff tears: outcome and analysis of factors associated with healing failure or poor postoperative function. Am J Sports Med 41(7):1674-1683

35. Fermont AJ, Wolterbeek N, Wessel RN, Baeyens JP, de Bie RA (2014) Prognostic factors for successful recovery after arthroscopic rotator cuff repair: a systematic literature review. J Orthop Sports Phys Ther 44(3): 153-163

36. De Luca CJ, Sabbahi MA, Roy SH (1986) Median frequency of the myoelectric signal. Effects of hand dominance. Eur J Appl Physiol 53:457-464

37. Zijdewind C, Bosch W, Goessens L, Kandou TWA, Kernell D (1990) Electromyogram and force during stimulated fatigue tests of muscles in dominant and non-dominant hands. Eur J Appl Physiol 60:127-132

38. Hagemann G, Rijke AM, Mars M (2004) Shoulder pathoanatomy in marathon kayakers. Br J Sports Med 38(4):413-417

39. Tashjian RZ, Farnham JM, Albright FS, Teerlink CC, CannonAlbright LA (2009) Evidence for an inherited predisposition contributing to the risk for rotator cuff disease. J Bone Joint Surg Am 91(5):1136-1142

40. Fujita S, Masago K, Hatachi Y, Fukuhara A, Hata A, Kaji R, Kim YH, Mio T, Mishima M, Katakami N (2010) Genetic polymorphisms in the endothelial nitric oxide synthase gene correlate with overall survival in advanced non-small-cell lung cancer patients treated with platinum-based doublet chemotherapy. BMC Med Genet 11:167

41. Lin J, Wang MX, Wei A, Zhu W, Murrell GA (2001) The cell specific temporal expression of nitric oxide synthase isoforms during achilles tendon healing. Inflamm Res 50(10):515-522

42. de Girolamo L, Stanco D, Galliera E, Viganò M, Lovati AB, Marazzi MG, Romeo P, Sansone V (2014) Soft-focused extracorporeal shock waves increase the expression of tendon-specific markers and the release of anti-inflammatory cytokines in an adherent culture model of primary human tendon cells. Ultrasound Med Biol 40(6):1204-1215

43. Handa RK, Evan AP (2010) A chronic outcome of shock wave lithotripsy is parenchymal fibrosis. Urol Res 38(4):301-305

44. Chen YJ, Wurtz T, Wang CJ, Kuo YR, Yang KD, Huang HC, Wang FS (2004) Recruitment of mesenchymal stem cells and expression of TGF-beta 1 and VEGF in the early stage of shock wave-promoted bone regeneration of segmental defect in rats. J Orthop Res 22(3):526-534

45. Berta L, Fazzari A, Ficco AM, Enrica PM, Catalano MG, Frairia $\mathrm{R}$ (2009) Extracorporeal shock waves enhance normal fibroblast proliferation in vitro and activate mRNA expression for TGFbeta1 and for collagen types I and III. Acta Orthop 80(5):612-617

46. Chung SW, Park JS, Kim SH, Shin SH, Oh JH (2012) Quality of life after arthroscopic rotator cuff repair: evaluation using SF-36 and an analysis of affecting clinical factors. Am J Sports Med 40:631-639

47. Burgess KE, Pearson SJ, Onambélé GL (2010) Patellar tendon properties with fluctuating menstrual cycle hormones. J Strength Cond Res 24(8):2088-2095

48. Kim EH, Heo CY (2014) Current applications of adipose-derived stem cells and their future perspectives. World J Stem Cells 6(1):65-68

49. Gerdersmeyer L, Maier M, Haake M, Schmitz C (2002) Physikalisch-technische Grundlagen der extrakorporalen Stoßwellentherapie (ESWT). Der Orthopäde 31:610-617
50. Rompe JD, Küllmer K, Vogel J, Eckardt A, Wahlmann U, Eysel P, Hopf C, Kirkpatrick CJ, Bürger R, Nafe B (1997) Extracorporeal shock-wave therapy. Experimental basis, clinical application. Orthopade 26(3):215-228

51. Schofer MD, Hinrichs F, Peterlein CD, Arendt M, Schmitt J (2009) High- versus low-energy extracorporeal shock wave therapy of rotator cuff tendinopathy: a prospective, randomised, controlled study. Acta Orthop Belg 75(4):452-458

52. Al-Abbad H, Simon JV (2013) The effectiveness of extracorporeal shock wave therapy on chronic Achilles tendinopathy: a systematic review. Foot Ankle Int 34(1):33-41

53. Rompe JD, Furia J, Maffulli N (2009) Eccentric loading versus eccentric loading plus shock-wave treatment for midportion achilles tendinopathy: a randomized controlled trial. Am J Sports Med 37(3):463-470

54. Wren TA, Yerby SA, Beaupré GS, Carter DR (2001) Influence of bone mineral density, age, and strain rate on the failure mode of human Achilles tendons. Clin Biomech (Bristol, Avon) 16(6):529-534

55. Ryan ED, Herda TJ, Costa PB, Herda AA, Cramer JT (2014) Acute effects of passive stretching of the plantarflexor muscles on neuromuscular function: the influence of age. Age (Dordr) 36(4):9672

56. Plate JF, Brown PJ, Walters J, Clark JA, Smith TL, Freehill MT, Tuohy CJ, Stitzel JD, Mannava S (2014) Advanced age diminishes tendon-to-bone healing in a rat model of rotator cuff repair. Am J Sports Med 42(4):859-868

57. Maman E, Harris C, White L, Tomlinson G, Shashank M, Boynton E (2009) Outcome of nonoperative treatment of symptomatic rotator cuff tears monitored by magnetic resonance imaging. J Bone Joint Surg Am 91:1898-1906

58. Baysal D, Balyk R, Otto D, Luciak-Corea C, Beaupre L (2005) Functional outcome and health-related quality of life after surgical repair of full-thickness rotator cuff tear using a mini-open technique. Am J Sports Med 33:1346-1355

59. Grondel RJ, Savoie FH 3rd, Field LD (2001) Rotator cuff repairs in patients 62 years of age or older. J Shoulder Elbow Surg 10:97-99

60. Rebuzzi E, Coletti N, Schiavetti S, Giusto F (2005) Arthroscopic rotator cuff repair in patients older than 60 years. Arthroscopy 21:48-54

61. Watson EM, Sonnabend DH (2002) Outcome of rotator cuff repair. J Shoulder Elbow Surg 11:201-211

62. Gaida JE, Ashe MC, Bass SL, Cook JL (2009) Is adiposity an under-recognized risk factor for tendinopathy? A systematic review. Arthritis Rheumatol 61(6):840-849

63. Rechardt M, Shiri R, Karppinen J, Jula A, Heliövaara M, ViikariJuntura E (2010) Lifestyle and metabolic factors in relation to shoulder pain and rotator cuff tendinitis: a population-based study. BMC Musculoskelet Disord 20(11):165

64. Abboud JA, Kim JS (2010) The effect of hypercholesterolemia on rotator cuff disease. Clin Orthop Relat Res 468(6):1493-1497

65. Holmes GB, Lin J (2006) Etiologic factors associated with symptomatic achilles tendinopathy. Foot Ankle Int 27(11):952-959

66. Ritchlin CT (2006) Therapies for psoriatic enthesopathy. A systematic review. J Rheumatol 33:1435-1438

67. Stahlmann R, Lode HM (2013) Risks associated with the therapeutic use of fluoroquinolones. Expert Opin Drug Saf 12(4):497-505

68. Cruzat V, Cuchacovich R, Espinoza LR (2010) Undifferentiated spondyloarthritis: recent clinical and therapeutic advances. Curr Rheumatol Rep 12:311-317

69. Oliva F, Berardi AC, Misiti S, Maffulli N (2013) Thyroid hormones and tendon: current views and future perspectives. Concise review. Muscles Ligaments Tendons J 3(3):201-203 
70. Oliva F, Berardi AC, Misiti S, Verza Felzacappa C, Iacone A, Maffulli N (2013) Thyroid hormones enhance growth and counteract apoptosis in human tenocytes isolated from rotator cuff tendons. Cell Death Dis 4:e705

71. Everitt AV, Porter BD, Steele M (1981) Dietary, caging and temperature factors in the ageing of collagen fibres in rat tail tendon. Gerontology 27(1-2):37-41
72. Jozsa L, Balint JB, Kannus P, Reffy A, Barzo M (1989) Distribution of blood groups in patients with tendon rupture. An analysis of 832 cases. J Bone Joint Surg Br 71:272-274

73. Namdari S, Donegan RP, Chamberlain AM, Galatz LM, Yamaguchi K, Keener JD (2014) Factors affecting outcome after structural failure of repaired rotator cuff tears. J Bone Joint Surg Am 96(2):99-105 